Original Research Paper

\title{
Theoretical Context of the Nuclear Posture Review
}

\author{
${ }^{1}$ Timothy Sands, ${ }^{2}$ Richard Mihalik and ${ }^{3}$ Harold Camacho \\ ${ }^{1}$ Department of Mechanical Engineering, Stanford University, USA \\ ${ }^{2}$ Department of Microbiology, University of Texas, USA \\ ${ }^{3}$ Department of History, San Diego State University, USA
}

Article history

Received: 11-03-2018

Revised: 17-03-2018

Accepted: 24-03-2018

Corresponding Author:

Timothy Sands

Department of Mechanical

Engineering, Stanford

University, USA

Tel.: +1-831-656-3954

Email: dr.timsands@stanford.edu

\begin{abstract}
The very recently published 2018 American Nuclear Posture Review hails the revived emphasis on deployed, low-yield nuclear options to reserve credible deterrence against countries that have transmitted beliefs the U.S. would not respond to employment of non-strategic nuclear weapons, since there is a mistaken perception that the U.S. could only respond with high-yield strategic weapons, which would be deemed unacceptable. This research briefly evaluates this newly published development in light of the enduring theoretical debates in the literature concluding the possible potential to lower the threshold for first-use of these weapons, but identifying active mitigation efforts. The research is intended merely to begin a discussion in the literature of the new nuclear posture in context of the predominant theories in international relations and conflict.
\end{abstract}

Keywords: Low-Yield, Nuclear Posture Review, Escalation, De-Escalation, Rational Actor, Organizational Theory, Nuclear Deterrence

\section{Introduction}

Nuclear war is a horrific contemplation especially with our knowledge of nuclear weapon employment in World War II, followed by the development of weapons with staggering destructive capabilities that eclipsed many other factors in international relations for decades leading to a bi-polar world, where countries allied with major nuclear powers. Paradigms change with the natural passage of time and the occurrence of major world events, like the dissolution of the Soviet Union, or the recent resurgent Russia. These major events drive the formulation of national policies and one such major policy has just been published by the United States: The 2018 Nuclear Posture Review. Theories of international relations and conflict, particular theories on nuclear deterrence provide guiding windows through which we gaze upon the new nuclear posture review, which is clearly a reaction to a strategic mismatch in capabilities between the United States and other world power, Russia in particular (as it relevant to this investigation).

\section{Materials and Methods: Assertions and their Theoretical Context}

A key challenge of modern nuclear deterrence is the non-strategic nuclear capabilities of Russia. Figure 1, taken directly from the nuclear posture review pictorially reveals the mismatch and uses this mismatch as the backdrop of assertions that Russia believes limited nuclear first-use, particularly with low-yield weapons provides a deterrent advantage over the United States based in part on Moscow's perception that it a mismatch in non-strategic options provides coercive advantages at low-levels of conflict. Interestingly, two assertions are made...separated by only one paragraph. Firstly, it is asserted that the evolving Russian nuclear doctrine based in this mismatch lowers the threshold for their first-use of nuclear weapons and then secondly asserted is expanding U.S. low-yield, non-strategic nuclear capabilities will not lower the threshold of American first-use of nuclear weapons.

How can both assertions be simultaneously true? Low-yield nuclear weapons either do, or do-not lower the threshold of first use. Perhaps a brief literature review can illuminate how both assertions might be simultaneously true.

Literature Review: Rational Actor Versus Organization Theory of Deterrence

\section{Rational Deterrence Theory}

Theorems and corollary in this section derive from (Waltz, 1981), (Lamb, 2015) and are paraphrased for brevity and ease to the reader. 


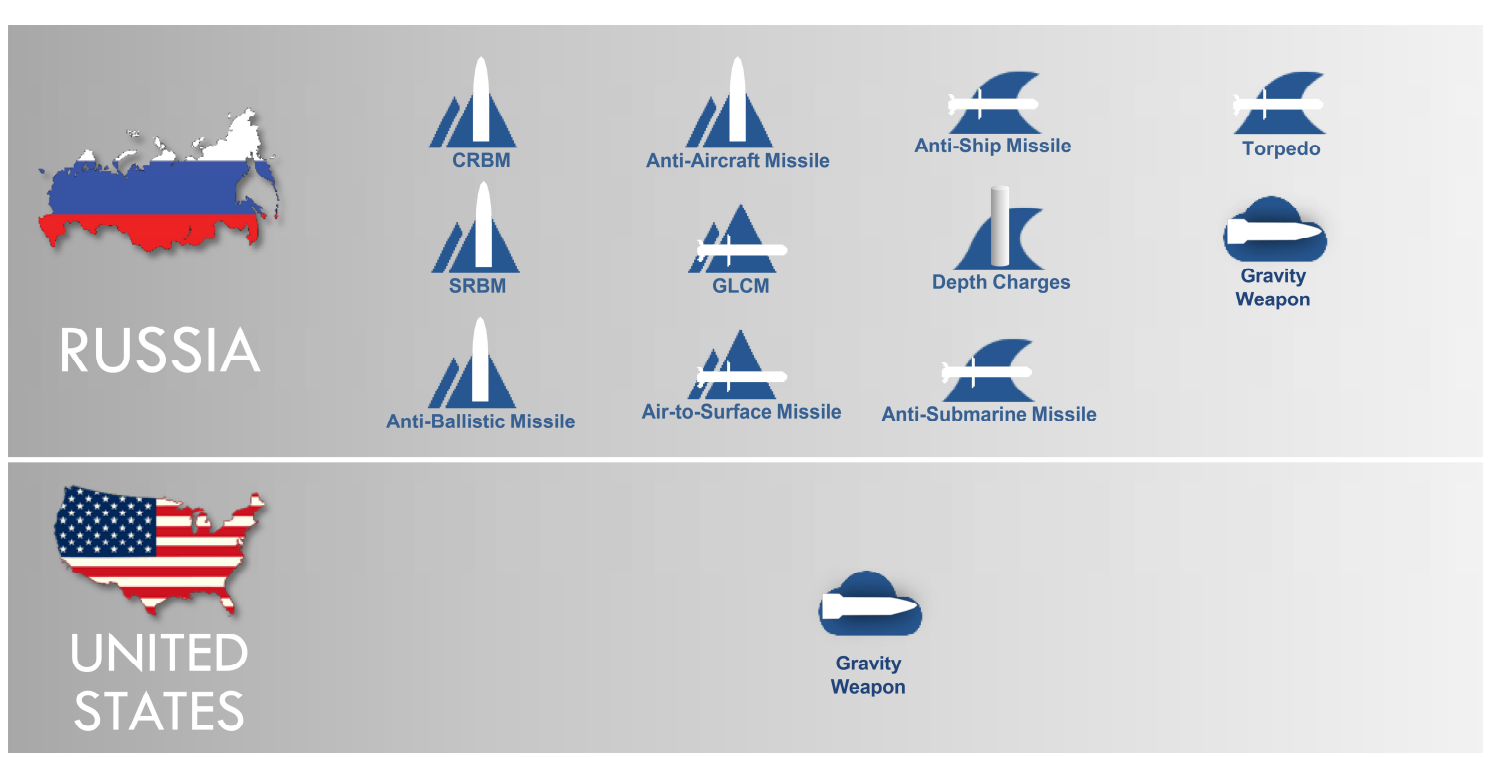

Fig. 1: The mismatch in capabilities to be addressed by the nuclear posture review

\section{Theorem 1 Rational Actor Theorem}

All states are inherent rational actors that are deterred from conflict escalation by other states that acquire nuclear-weapons capabilities.

\section{Proof(s) of Theorem 1}

The United States and the Soviet Union were successfully deterred from direct conflict by simultaneous possession of nuclear weapons. North Korea developed nuclear weapons and in response no nation or group of nations has dared intervene. They seem deterred from military action against North Korea.

\section{Corollary 1 to Rational Actor Theorem}

States are inherent rational actors that are not deterred from conflict escalation by other states that go not acquire nuclear-weapons capabilities.

\section{Proof(s) of Corollary to Theorem 1}

Libya gave up their nuclear weapons pursuit and subsequently one decade later NATO intervened in Libya resulting in Gaddafi's overthrow and killing. NATO was not deterred by a non-nuclear armed Libya. Ukraine gave up their nuclear weapons in exchange for protective assurances and shortly afterwards Russia annexed part of Ukraine's territory with no effective defensive response by NATO.

\section{Organizational Theory of Deterrence}

Theorems and corollary in this section derive from (Sagan, 1994) and are paraphrased for brevity and ease to the reader.

\section{Theorem 2}

Organizational Theorem. Professional military organizations, because of common biases, inflexible routines and parochial interests-display strong proclivities toward organizational behaviors that lead to deterrence failures. If left on their own, these organizations are unlikely to fulfill the operational requirements for rational nuclear deterrence and such organizational proclivities can be effectively countered only by tight and sustained civilian control of the military.

\section{Proof of Theorem 2}

The United States, China and Soviet Union have maintained tight control over their militaries and have substantiated the operational requirements for rational nuclear deterrence. Former Soviet satellite nations who did not necessarily have such tight control were quick to give up their nuclear weapons.

\section{Further Elaboration}

The contending theorems and proofs are elaborated beyond (Waltz, 1981) in "The Spread of Nuclear Weapons: A debate renewed" (Sagan and Waltz, 2002) in the context of proliferation. A very good book review (Lamb, 2015) is available to permit the reader to briefly evaluate some key details:

Waltz: Rational deterrence theory:

- There is a fundamental difference between conventional and nuclear worlds.

- Gradual spread of nuclear weapons is better than no spread or rapid spread.

- Nuclear weapons make war less likely, because nuclear weapons encourage both defense and 
deterrence. The possibility (however remote) and unacceptably high cost of destruction makes states more careful and miscalculation difficult

- Given second-strike capabilities, the balance of forces isn't what counts - (asymmetric capabilities ok, just a threat ok, credibility need not be proven)

- Not only do nukes deter attacks on the homeland, they deter attacks on any vital strategic interests, lowers the stakes of war, intensity of war

- Weaker states are not more likely to use nukes irresponsibly - they would lose in a conventional war, so they need to save their nukes - they will only use them if survival is at stake, not for irresponsible aggression

- Even Hitler would have been deterred if Germany had faced nuclear weapons

- Even if not, one man can't make a war - his generals would have stopped him

- Madman theory is defunct

- The last thing anyone wants to do is make a nuclear nation desperate - so nukes affect the deterrer and the deterred

- You can't totally stop the spread - each state will always strive to seek its own security

- Even terrorists are not irrational. Just as unlikely to use nukes as weak states if they do manage to get them

Sagan: Bureaucratic politics (organizational) theory:

- Military organizations, unless managed by strong civilian-control institutions, will display organizational behaviors that are likely to lead to deterrence failures and deliberate or accidental war, because of common biases, inflexible routines and parochial interests

- Future nuclear-armed states will likely lack the requisite civilian control mechanisms and military interests, not objective interests, will dominate

- Talks at length about characteristics of military organizations (offensive culture, operational culture, etc.) and conditions fostering instability (hair trigger alert, inflexible routines that undermine development of second-strike capability) - all of these play into undermining three assumptions/assertions made by Waltz

- There must not be preventive war during the period of building nukes, 2. Both states must develop second-strike capability and survivability, 3 . Nuclear arsenals must not be prone to accidental use

\section{Results and Discussion}

Examine the nuclear posture review's assertion the evolving Russian nuclear doctrine based in a mismatch of low-yield tactical nuclear weapons lowers the threshold for their first-use of nuclear weapons, yet simultaneously evaluate the assertion expanding U.S. low-yield, non-strategic nuclear capabilities will not lower the threshold of American first-use of nuclear weapons. The examinations take place in light of the aforementioned rational actor theory versus the organization theory of nuclear deterrence.

\section{Implications of the Literature Review}

The rational actor theory supports a perception that Russia has increased incentive for first-use of low-yield tactical nuclear weapons in instances where a rationalAmerica would not be willing to respond with much more destructive, higher-yield strategic weapons. Thus, increased American emphasis in the nuclear posture review on the development of some (not seeking parity) low-yield capabilities does indeed incentivize American first-use, particularly since parity is not sought and thus superiority in number is unlikely.

On the other hand, the organizational theory of nuclear deterrence leads to some different conclusions dependent upon the assumptions of stable control of the military. Increased emphasis on low-yield nuclear weapons is tempting for military organizations with inherent strong proclivities toward organizational behaviors that lead to deterrence failures. America currently has granted increased autonomy to its military compared to recent years, so it is arguable that the threshold for first-use by America is lowered by simultaneously granting the military increased autonomy and issuing the military more low-yield options, since they are inherently more realistically employable. Russia on the other hand has no recent changes in military relationships with civilian control that seem to alter their paradigm for first-use.

\section{The World Following Publication of the Nuclear Posture Review}

In light of these two theories, the future holds at best, no-change in the threshold of first-use of nuclear weapons, as is the case with the rational actor theory; or at worst an increased likelihood of American first use in instances where a targeted nation has no strong alliance with Russia. In a similar contextual comparison, comparable results are seen against the backdrop of the theories of Kahn and Schelling (Sands, Mihalik et al., 2018).

In light of the failures seen at the 2010 and 2015 nuclear nonproliferation treaty review conferences (Sands and Mihalik, 2016), proliferation concern is increased by an increase in development of small-yield tactical nuclear weapons in America, where relative freedom accompanies increased risk of scientist and engineers involved in those efforts becoming proliferation risks themselves (e.g. through technology transfer). 
Another complicating factor is the admission that the United States has found itself preoccupied for many years with the Middle East, most recently with the Islamic State (Sands, 2016). It begs the question "is the next generation of Americans prepared to go down this path of increased tactical nuclear options?" Seemingly in answer to the question, the U.S. Air Force has already begun an earnest effort to increase the critical thinking capabilities of its nuclear enterprise (Sands et al., 2017) vis-à-vis rigorous education programs available parttime, using distance learning technologies to educate increasingly larger portions of the air force's nuclear members. These new education programs are designed to expose nuclear forces to the theorems and proofs presented in this manuscript in accordance with a new education paradigm described in paragraph 3.1 in (Mihalik et al., 2017). Professor Sagan's course is specifically included on the list of available courses (Sands, Mihalik, 2016). In addition to the arguments in the social sciences, the air force is reinvigorating scientific education efforts towards all military missions in and through space (Nakatani, 2018), (Sands, 2018), (Kim et al., 2007), (Nakatani, 2016), (Sands, 2009) including nuclear systems. This undertaking requires significant refocusing towards recent technical developments (Sands, 2012), (Cooper, 2017), (Nakatani, 2014), (Sands, Kenny, 2017), (Sands, Armani, 2018), (Sands, 2017) the critical thinking ability of american nuclear forces. One particular area of emphasis is the technology to maneuver reentry warheads (Sands, 2006), (Sands, 2012), (Sands, Kim et al., 2016), (Sands, Kim et al., 2018) to avoid missile defenses (Sands, Lu et al., 2018).

\section{Conclusion}

In light of two competing theories, the American declaration to increase its utilization of low-yield nuclear weapons to meet its deterrence objectives has the possible potential to lower the threshold for first-use of these weapons, but this potential is being actively mitigated by current efforts to increase the capabilities of the military members, possibly positioning them to avoid the organizational proclivities that might prevent fulfillment of the operational requirements for rational nuclear deterrence.

\section{Acknowledgement}

The authors declare no conflict of interest.

\section{Author Contributions}

Sands, Camacho, and Mihalik conceived and evaluated the arguments; Sands, Camacho, and Mihalik analyzed the results; Sands wrote the paper; while Sands, Camacho, and Mihalik edited the paper until publication.
Authorship has been limited to those who have contributed substantially to the work.

\section{Conflicts of Interest}

The authors declare no conflict of interest.

\section{References}

Cooper, M., P. Heidlauf and T. Sands, 2017. Controlling Chaos-Forced van der Pol Equation. Mathematics, 5: 70-80. DOI: 10.3390/math5040070

Kim, J., T. Sands and B. Agrawal, 2007. Acquisition, tracking, and pointing technology development for bifocal relay mirror spacecraft. Proc. SPIE, 6569. DOI: $10.1117 / 12.720694$

Lamb, P.K., 2015. Harvard Book review: Sagan, Scott D. and Kenneth N. Waltz. The Spread of Nuclear Weapons: A Debate Renewed, New York: W.W. Norton, 1995, downloaded from Harvard website, "IR Generals Review Notes 2007".

Mihalik, R., H. Camacho and T. Sands, 2017. Continuum of learning: Combining education, training and experiences. Education, 8: 9-13. DOI: $10.5923 /$ j.edu.20180801.03

Nakatani, S., 2014. Simulation of spacecraft damage tolerance and adaptive controls, Proc. IEEE Aero., 116. DOI: 10.1109/AERO.2014.6836260.

Nakatani, S., 2016. Autonomous damage recovery in space. Intl. J. Auto. Contr. Intell. Sys., 2: 22-36. ISSN Print: 2381-75.

Nakatani, S., 2018. Battle-damage tolerant automatic controls. Elec. Electr. Eng., 8: 10-23. DOI: 10.5923/j.eee.20180801.02.

Sagan, S.D., 1994. The perils of proliferation organization theory, deterrence theory and the spread of nuclear weapons. Int. Security, 18: 66-107.

Sagan, S.D. and K.N. Waltz, 2002. The Spread of Nuclear Weapons: A Debate Renewed. 1st Edn., W.W. Norton, New York.

Sands, T, Kim, J., Agrawal, B., 2006. 2H Singularity free momentum generation with non-redundant control moment gyroscopes. Proc. IEEE CDC. 1551-1556. DOI: $10.1109 /$ CDC.2006.377310

Sands, T., 2009. Satellite electronic attack of enemy air defenses. Proc. IEEE CDC. 434-438. DOI: 10.1109/SECON.2009.5174119

Sands, T., 2012. Physics-based control methods. Adv. Space. Sys. Orb. Det., InTech, London. DOI: $10.5772 / 2408$

Sands, T., J. Kim and B. Agrawal, 2012. Nonredundant single-gimbaled control moment gyroscopes. J. Guid. Dyn. Contr., 35: 578-587. DOI: 10.2514/1.53538.

Sands, T., J. Kim and B. Agrawal, 2016. Experiments in Control of Rotational Mechanics. Intl. J. Auto. Contr. Intel. Sys., 2: 9-22. 
Sands, T. and R. Mihalik, 2016. Outcomes of the 2010 and 2015 nonproliferation treaty review conferences. World J. Soc. Sci. Humanities, 2: 46-51. DOI: 10.12691/wjssh-2-2-4

Sands, T., 2016. Strategies for combating Islamic state. Soc. Sci., 5: 39-39. DOI: 10.3390/socsci5030039.

Sands, T., 2017. Nonlinear-adaptive mathematical system idenfication. Computation, 5: 47-59. DOI: 10.3390/computation5040047

Sands, T., 2017. Space systems identification algorithms. J. Space Expl., 6: 138-149

Sands, T., H. Camacho and R. Mihalik, 2017. Education in nuclear deterrence and assurance. J. Def. Manag., 7: 166-166. DOI: 10.4172/2167-0374.1000166.

Sands, T. and T. Kenny, 2017. Experimental piezoelectric system identification, J. Mech. Eng. Auto, 7: 179-195. DOI: 10.5923/j.jmea.20170706.01
Sands, T., 2018. Space mission analysis and design for electromagnetic suppression of radar. Intl. J. Electromag. and Apps., 8: 1-25. DOI: 10.5923/j.ijea.20180801.01

Sands, T. and C. Armani, 2018. Analysis, correlation, and estimation for control of material properties. J. Mech. Eng. Auto. 8: 7-31, DOI: 10.5923/j.jmea.20180801.02

Sands, T., J. Kim and B. Agrawal, 2018. Singularity Penetration with Unit Delay (SPUD). Mathematics, 6: 23-38. DOI: 10.3390/math6020023

Sands, T., D. Lu, J. Chu and B. Cheng, 2018. Developments in angular momentum exchange. Intl. J. Aero. Sci., 6: 1-6.

Waltz, K.N., 1981. The spread of nuclear weapons: Int. Institute Strategic Stud. 